\title{
Cognitive Functions Mediate the Effect of Preterm Birth on Mathematics Skills in Young
}

\section{Children}

Julia Anna Adrian1,2, Roger Bakeman3, Natacha Akshoomoff2,4, and Frank Haist2,4

1Department of Cognitive Science, UC San Diego

2Center for Human Development, UC San Diego

3Department of Psychology, Georgia State University

4Department of Psychiatry, UC San Diego

Correspondence concerning this article should be addressed to Julia Anna Adrian, UC

San Diego Cognitive Science 9500 MC 0515 Gilman Dr. La Jolla, CA 92093-0515. E-mail:

jadrian@ucsd.edu 


\begin{abstract}
Children born preterm are at risk for cognitive deficits and lower academic achievement. Notably, mathematics achievement is generally most affected. Here, we investigated the cognitive functions mediating early mathematics skills and how these are impacted by preterm birth. Healthy children born preterm (gestational age at birth $<33$ weeks; $n=51$ ) and children born full term $(n=27)$ were tested at ages 5,6 , and 7 years with a comprehensive battery of tests. We categorized items of the TEMA-3: Test for Early Mathematics Abilities Third Edition into number skills and arithmetic skills. Using multiple mediation models, we assessed how the effect of preterm birth on mathematics skills is mediated spatial working memory, inhibitory control, visual-motor integration, and phonological processing. Both number and arithmetic skills showed group differences, but with different developmental trajectories. The initial poorer performance observed in the preterm children decreased over time for number skills but increased for arithmetic skills. Phonological processing, visual-motor integration, and inhibitory control were poorer in children born preterm. These cognitive functions, particularly phonological processing, had a mediating effect on both types of mathematics skills. These findings help define and chart the trajectory of the specific cognitive skills directly influencing math deficit phenotypes in children born very preterm. This knowledge provides guidance for targeted evaluation and treatment implementation.
\end{abstract}

Key words: Preterm birth, mathematics, cognitive functions, phonological processing, mediation, development 


\section{Cognitive Functions Mediate the Effect of Preterm Birth on Mathematics Skills in Young Children}

Preterm birth (before 37 weeks of gestation) occurs in about $10 \%$ of all live births (Chawanpaiboon et al., 2019) and can be associated with brain injury and other health issues (Ramachandrappa \& Jain, 2009; Volpe, 2009). Advances in neonatal medical care have improved survival rates and severity of health outcomes (Grytten et al., 2017). Nevertheless, even in the absence of severe disabilities, children born preterm often suffer from developmental, cognitive, and behavioral problems (Anderson, 2014).

Children born preterm before 33 weeks of gestation are especially at increased risk for deficits in cognitive functions and academic achievement (Johnson, Wolke, Hennessy, \& Marlow, 2011), specifically in mathematics (Aarnoudse-Moens, Oosterlaan, Duivenvoorden, van Goudoever, \& Weisglas-Kuperus, 2011; Akshoomoff et al., 2017; Taylor, Espy, \& Anderson, 2009). Lower educational outcomes following this level of preterm birth have been reported in early school age (Pritchard et al., 2009; Taylor et al., 2018), adolescence (Litt et al., 2012; Rose, Feldman, \& Jankowski, 2011), and adulthood (Løhaugen et al., 2010). Little is known about the developmental trajectory of emerging mathematics skills in preterm children.

In the general population, school-entry mathematics skills are a strong predictor of later academic achievement (Duncan et al., 2007). Middle-school mathematics skills have been shown to mediate the relationship between preterm birth and adult wealth (Basten, Jaekel, Johnson, Gilmore, \& Wolke, 2015). Here we focus on the development of mathematics skills in the critical early school-age period.

\section{Mathematics Comprises Multiple Skills}

One major issue regarding the study of children's early mathematics development is that it 
is often seen as one skill, rather than the variety of different skills that constitute mathematics ability. Standardized achievement tests used with children and adults are typically designed to span a wide age range, sample a broad array of academic skills based on age expectations, and provide one overall score (e.g. Woodcock, McGrew, \& Mather, 2007). In younger children, the Test for Early Mathematics Ability, Third Edition (TEMA-3, Ginsburg \& Baroody, 2003) has been used in studies of typically and atypically developing children (Fuhs \& McNeil, 2013; Hasler \& Akshoomoff, 2019; Kull \& Coley, 2015; Mazzocco, Feigenson, \& Halberda, 2011; Schneider et al., 2017). While most studies used the overall scaled Mathematics Ability Score to assess children's performance, the TEMA-3 also provides raw scores of "informal" and "formal" mathematics abilities. Informal mathematics abilities include numbering, counting, magnitude comparisons, and using fingers or other markers to solve simple arithmetic problems. In comparison, formal math skills are abilities learned in school including the understanding and use of numerals, exact magnitude specification, and memorized facts for addition, subtraction, and multiplication. Libertus, Feigenson, \& Halberda (2013) found that young children's numerical approximation abilities predicted their informal but not formal mathematics abilities. While the TEMA-3 informal and formal distinction is useful, it is based on descriptive face-valid qualities. In this study, we followed the guidance from Ryoo and colleagues (2015) to create categories of specifically defined math skills. Two types of mathematics skills were defined (see Table 1): (a) number skills, including items that are related to the ordering based on numerical magnitudes such as counting and number comparison skills (28 items), and (b) arithmetic skills, including items that are related to manipulation of numbers such as calculation skills with problems that are presented in story form or via equations (36 items). While test items in these categories require distinct sets of skills, number and arithmetic skills do not develop independent 
from each other. During early school age, arithmetic skills have been shown to be predicted by (particularly symbolic) number skills (Lyons, Price, Vaessen, Blomert, \& Ansari, 2014).

\section{Distinct Cognitive Functions Contribute to Mathematics Skills}

Mathematics performance requires the integration of a complex set of skills. Previous work has identified working memory and inhibitory control, visual-motor integration, and phonological processing as critical components contributing to mathematics abilities (De Smedt et al., 2010; Geary \& Moore, 2016; Kulp, 1999). A specific cognitive function might be more important for one type of mathematics skill than for another one. For example, Lan, Legare, Ponitz, Li, \& Morrison (2011) found that working memory uniquely predicted calculation skills in preschoolers, while counting skills were predicted both by working memory and inhibition. Dividing mathematics skills into number and arithmetic skills thus provides the opportunity to study the influence of cognitive functions on specific mathematics skills, particularly those functions that are impacted by preterm birth.

Executive functions are a robust predictor of mathematics skills in full-term and preterm children. In a longitudinal study of over 1200 typically developing children, Ribner, Willoughby, $\&$ Blair (2017) found that executive function skills at age 5 strongly predicted mathematics achievement in 5th grade. Working memory might underpin mathematics skills when it is necessary to mentally retain and retrieve relevant information. Inhibitory control may contribute more to the suppression of inappropriate but mentally prevalent answers or strategies (Bull \& Lee, 2014). Rose et al. (2011) suggested a cascade of effects from prematurity to slower processing speed, to poorer executive functions (working memory), and finally lower academic achievement, after examining 11-year-old preterm children with a birth weight of $<1750 \mathrm{~g}$. 
Executive function deficits were also reported in 3-5 year old preterm children and found to meditate the effect of gestational age on behavioral problems (Loe, Feldman, \& Huffman, 2014).

Visual-motor integration has not been studied extensively but is a potential mediator between preterm birth and low mathematics performance because preterm children have an increased risk of visual-motor integration deficits (Geldof, van Wassenaer, de Kieviet, Kok, \& Oosterlaan, 2012).. Deficits in visual-motor integration have been shown to be associated with lower mathematics performance in typically developing children (Sortor \& Kulp, 2003). A recent study of children born extremely preterm (before 28 weeks gestation) showed involvement of visual-motor integration in mathematics performance (Taylor et al., 2018).

In addition, verbal skills contribute to mathematics performance. Language functions are involved when solving mathematics problems, for example through representation and manipulation of magnitudes in form of number words. Specifically, the extant literature shows that phonological processing makes a specific contribution to mathematics abilities.

Phonological processing includes the ability to perceive, produce, discriminate, and manipulate specific sounds of a language. In a typically developing cohort, phonological difficulty at age 5 was associated with deficits in formal mathematics components at age 7 (Jordan, Wylie, \& Mulhern, 2010). Phonological awareness is a specific part of phonological processing that describes the ability to concatenate and remove phonological segments to form words. De Smedt, Taylor, Archibald, \& Ansari (2010) reported a specific and unique association between phonological awareness and single-digit arithmetic skills in typically developing children at age 10. Deficits in phonological awareness, phonological processing, and other language outcomes have been reported in preterm children (Vohr, 2014), though fewer studies have investigated the link between phonology and mathematics in preterm children. 
Most studies investigating mathematics performance in full-term and preterm children examine overall performance on standardized mathematics tests, which include a variety of different skills. It is thus difficult to understand which specific mathematics skills are affected at different ages. It remains an open question whether number and arithmetic skills are differentially affected by preterm birth and if other cognitive functions, such as working memory, inhibitory control, visual-motor integration, and phonological processing are related to these mathematics skills. We chose to examine these particular cognitive functions based on recent research linking them to mathematics skills in children who were born preterm (Hasler \& Akshoomoff, 2019; Tatsuoka et al., 2016; Taylor et al., 2018; van Veen, van WassenaerLeemhuis, van Kaam, Oosterlaan, \& Aarnoudse-Moens, 2019). Furthermore, studies that investigate the effect of cognitive functions on mathematics skills often only study one of those functions (e.g. working memory) at a time. This does not allow us to understand how large the effects of these cognitive functions are in comparison to one another.

Our study first compared the status of number skills and arithmetic skills in children born preterm and full-term. Next, using mediation analysis, we determined which cognitive functions mediated the relationship between preterm birth and mathematics skills. Our study addresses limitations in prior research by including multiple cognitive functions in the same model, namely working memory, inhibitory control, visual-motor integration, and phonological processing.

\section{Method}

\section{Participants}

We recruited 51 children born preterm (24-32 weeks gestational age) and 27 children born full-term (38-41 weeks gestational age). Participant characteristics are summarized in Table 2. By definition, the preterm group had a significantly lower gestational age at birth and birth 
weight. There were no significant group differences in terms of sex, age at testing, household income, and race. Maternal education was lower in children born preterm compared to full-term.

The preterm participants were recruited primarily from the UC San Diego High-Risk Infant Follow Up Clinic. Inclusion criteria for the preterm sample were gestational age at birth of $<33$ weeks and absence of severe congenital, physical or neurological disabilities. Children were excluded if they had a history of severe brain injury (intraventricular hemorrhage of grade 3-4, cystic periventricular leukomalacia, moderate-severe ventricular dilation), genetic/chromosomal abnormalities affecting development, severe disability (e.g. bilateral blindness, cerebral palsy), or acquired neurological disorders unrelated to preterm birth. Of the 51 children born preterm, 10 were born extremely preterm ( $<28$ weeks of gestation); additionally, 16 children were born with very low birth weight $(1000 \mathrm{~g}-1500 \mathrm{~g})$ and 17 with extremely low birth weight $(<1000 \mathrm{~g})$. Six preterm participants had intraventricular hemorrhage of grade 1-2 (later resolved), none had periventricular leukomalacia, five had bronchopulmonary dysplasia, and five were small for gestational age.

The full-term participants were recruited through the Center for Human Development at UC San Diego. Inclusion criteria for the full-term sample were gestational age at birth of > 37 weeks and no history of neurological, psychiatric, or developmental disorders. Additionally, all participants were required to be native English speakers. As the data of this study is part of a larger project that includes MRI imaging, participants were excluded if they had a history of anxiety and/or metal implants that would interfere with scanning. The Institutional Review Board at UC San Diego approved the study. Legal guardians gave written informed consent, and children of age 7 years and older gave assent. 


\section{Design and Procedure}

We used a longitudinal design with each child receiving a comprehensive battery of cognitive and academic tests, health and demographic questionnaires and MRI imaging at three time points at approximate ages of 5, 6, and 7 years. Baseline testing was performed within six months of starting kindergarten, age at testing across the three assessments is described in Table 2. Partial behavioral and MRI results are described elsewhere (Hasler \& Akshoomoff, 2019; Hasler, Brown, \& Akshoomoff, 2019).

\section{Assessment of Mathematics Skills}

We assessed mathematics skills using the Test for Early Mathematics Ability, 3rd Edition (TEMA-3; Ginsburg \& Baroody, 2003). The TEMA-3 is designed for children between 3 and 8 years old and includes 72 items that a subset may be given based on age and performance. Overall performance is expressed in sum raw score of correct items and the standardized Mathematics Ability Score (mean=100, $\mathrm{SD}=15$ ). These measures are commonly used to characterize 'mathematics ability' in children. Ryoo et al. (2015) grouped the 72 test items from the TEMA-3 into seven categories: Verbal Counting, Counting Objects, Numerical Comparison, Set Construction, Calculation, Number Facts, Numeral Literacy that were validated by confirmatory factor analysis from their sample of 389 children. Their factor structure fit the longitudinal data better than the "formal" and "informal" TEMA-3 mathematics dichotomy. While the Ryoo et al. (2015) categorization scheme may be more theoretically useful, each of the seven categories contained only a small number of items and may be vulnerable to statistical instability. Furthermore, some of the items in different categories require the same type of skill. For example, items from the categories Set Construction, Calculation, and Number Facts all require the manipulation of numbers (arithmetic). Similarly, items in the Verbal Counting, 
Counting Objects, and Numerical Comparison clusters require ordering numbers based on the magnitudes they represent.

Based on the types of skills required to solve the problems, we clustered the TEMA-3 items by combining categories from Ryoo et al. (2015) into number skills and arithmetic skills (see Table 1). The category number skills comprises 28 items from the subcategories Verbal Counting, Counting Objects, and Numerical Comparison as defined by Ryoo et al. (2015). These items require the participant to order quantities by magnitude. The arithmetic skills category includes the 36 items from the subcategories Set Construction, Calculation, and Number Facts. These items require the participant to manipulate numbers to solve abstract and concrete (storyform) problems. One subcategory, Numeral Literacy, required participants to read and write numbers, a skill different from the other subcategories. These items were excluded from the present analyses.

\section{Assessment of Cognitive Functions}

\section{Spatial working memory}

We assessed spatial working memory via the Cambridge Neuropsychological Testing Automated Battery (CANTAB® Cognitive assessment software, 2017) Spatial Working Memory Task (SWM). This task is designed for participants from 4 to 99 years of age. It is a nonverbal, computerized task presented on a touch screen. The screen shows colored squares, the participant has to find a token that is hidden behind one of them. Once the token is found it is hidden again behind one of the squares under which it was not previously hidden. The participant has to use spatial working memory to successfully and efficiently find the hidden token and not search under the same square twice. Task difficulty increased by increasing the number of squares. Task performance is measured inversely through the number of errors made (number of squares that 
are searched multiple times, "between errors"). To simplify interpretation of the results, the inverse of this error measure is used for analysis, such that a more positive measure of SWM corresponds to better spatial working memory.

\section{Inhibitory control}

We assessed inhibitory control via the CANTAB Stop Signal Reaction Task (SST), designed for ages 4 to 99 years. It is a 'go/no-go' style nonverbal, computerized task presented on a touch screen. The participants see a circle in the center of the screen and one rectangle on either side of it. When an arrow appears on the screen, the participant's task is to touch the rectangle to which the arrow points as fast as possible. If they hear the auditory stop signal the participant has to inhibit their response and not touch the screen. Task performance is measured through the stop signal reaction time (SSRT). To simplify interpretation of the results and normalize the distribution, the inverse logarithm of this reaction time measure is used for analysis such that a more positive measure of the SST corresponds to higher inhibitory control.

\section{Visual-motor integration}

We assessed visual-motor integration using the Beery VMI 6th Edition (VMI; Beery, 2004), designed for ages 2 to 100 years. The participant's task is to copy geometric figures. There are specific scoring instructions for each item, resulting in 0 or 1 . The test is completed if three consecutive items were failed to be copied correctly. VMI raw scores were used in the analyses as the performance scores for the other cognitive and academic tasks were not adjusted for age.

\section{Phonological processing}

We assessed phonological processing via the Comprehensive Test of Phonological Processing Second Edition (CTOPP-2; Wagner, Torgesen, Rashotte, \& Pearson, 2013). The 
CTOPP-2 is designed for ages 4:0 through 24:11 and contains a variety of subtests assessing phonological awareness, phonological memory, rapid symbolic naming, and rapid non-symbolic naming. Here we used the Elision subtest, which has been widely used in clinical and typical populations to measure phonological awareness. The participant's task is to omit a phonological segment (syllable/phoneme) of a word that they previously heard and say the word out loud. The result is another existing word, e.g. "say 'always' without 'all'" [ways] or "say 'silk' without /1/" [sick]. Phonological awareness is measured as the sum of all correctly answered items out of a maximum of 34 .

\section{Statistical Analysis}

Statistical Analyses were performed with IBM SPSS Statistics (v. 26). Effect sizes were assessed for group comparisons: (partial) $\eta_{2}$ for non-parametric tests, ANOVAs and ANCOVAs, and Cramer's V for $\chi^{2}$ tests. Because mothers of preterm children reported less education on average then mothers of full-term children, we used maternal education as a covariate in our analyses.

We assessed the mediating effect of cognitive functions on mathematics skills with multiple mediation analyses. A multiple mediation model analyzes if and to what extent the effect of preterm birth on mathematics skills can be accounted for by the effect of preterm birth on cognitive functions, which in turn influence mathematics skills. Direct and mediated effects were evaluated based on their effect size.

The multiple mediation analyses assessed:

(1) the total effect model, which considers the total effect of preterm birth on the outcome variable. This does not include the mediators. 
(2) the direct (unmediated) effect of preterm birth on the outcome variable, when mediators are included.

(3) the indirect (mediating) effects of preterm birth on the outcome variable through the mediators.

We used separate multiple mediation models for the three testing times (age 5, 6, and 7 years) and both mathematics skills outcome variables (number and arithmetic skills), resulting in a total of six mediation models. Given the constraints of our relatively small sample, this crosssectional approach allowed us to remain descriptively close to our data while highlighting differences across the three ages in identical samples.

Due to the intercorrelations of group, maternal education, and cognitive functions, the effect of group can switch from being negative (lower performance in the preterm group) to positive (higher group average in the preterm group, when controlling for other variables in the model). This is because the other variables assume some of the variance that group accounted for when alone in the model.

\section{Results}

\section{Age and Group differences in mathematics skills and cognitive function}

Of primary interest are number and arithmetic skills_-our outcome variables. The other two mathematic skill variables-TEMA-3 overall, scaled and percentage — are included for comparison. In addition, the cognitive function variables were analyzed subsequently as potential mediating variables. Group means at the three ages, adjusted for maternal education, are shown for mathematics skills variables in Figure 1 and for cognitive function variables in Figure 2. Table 3 provides statistics for repeated measures, trend analyses of covariance with age as the 
repeated measure, term status (preterm vs. full-term) as the between-groups factor, and maternal education as the covariate.

Age and group interacted for the number and arithmetic skills: mean differences between preterm and full-term groups decreased with age for number skills but increased with age for arithmetic skills. A repeated measures ANCOVA with type of mathematics skill as additional within-subject-variable found a strong and statistically significant interaction between time, group, and type of skill $\left(\mathrm{F}[2,150]=18.10, p<.001\right.$, partial $\left.\eta_{2}=.194\right)$-indicating that the difference between the patterns for number and arithmetic skills-decreasing pre-term-full-term differences for number skills but increasing differences for arithmetic skills-was consequential. (The threshold for what we term small or weak, medium or moderate, and large or strong $\eta^{2}$ is $.01, .06$, and .14; Cohen, 1988.).

The number skills, arithmetic skills, and TEMA-3 overall raw score increased notably with age with linear trend effect sizes ranging from .19 to $.43, p s<.001$. As expected of a scaled score, the TEMA-3 overall scaled score did not show a linear trend. The mean scores of the preterm children were lower than the means from full-term children for all mathematics skills variables with effect sizes $\left(\eta^{2}\right)$ ranging from .076 to .145 (see Figure 1 and, for effect sizes, Table 3).

Scores for cognitive functions increased with age with linear trend effect sizes ranging from .54 to $.82, p s<.001$. The mean scores for preterm children were lower than scores for the full-term children; in particular, the largest effects were observed for VMI, less so for Elision, and SST, and least (and not significantly) for SWM (see Table 3 for effect sizes). Age and group did not interact. 


\section{Non-Parametric Analyses of Number and Arithmetic Skills}

Adjusting for maternal education, number skill scores were negatively skewed for the full-term group at age 6 and arithmetic skill scores were positively skewed for the preterm group at all ages (standardized skews $>2.58$ absolute). To check whether, apart from extreme scores, number and arithmetic skill scores were reasonably distributed, we examined box-and-whisker plots (see Figure 3). Such plots show distributions graphically, including extreme scores (defined as scores 1.5 times the interquartile range greater than the 75 th or less than the 25 th percentile; Tukey, 1977). The box-and-whisker plots confirm the pattern shown in Figure 1 that the difference between preterm and full-term medians, which are not influenced by extreme scores, decreased with age for the number skills scores (from 16.7, to 13.4, to 3.6) but increased with age for the arithmetic skills scores (from 0.7, to 6.9, to 19.4) for ages 5, 6, and 7, respectivley. We confirmed these impressions via non-parametric Mann-Whitney $\mathrm{U}$ tests showing that $p$ values increased from .008 , to .014 , to .047 for numeric skills but decreased from .052 , to <.001, to $<.001$ for arithmetic skills.

\section{Simple and Mediation Models Predicting Number and Arithmetic Skills}

Models predicting number skills for ages 5, 6, and 7 are shown in Figure 4; similar models predicting arithmetic skills are shown in Figure 5. Displayed first are two singlepredictor models, one with term status as the predictor and the other with maternal education as the predictor, thus their path coefficients are simple Pearson correlations coefficients ( $r$ s). Fullterm status was coded 0 and preterm status 1 , thus negative coefficients for group signal lower average outcome means for the preterm than the full-term group. The figures also show the percentage of variance not accounted for by each model (i.e., the error variance). 
Two-predictor, unmediated models — group and maternal education are the predictorsare displayed next; their path coefficients are the partial standardized coefficients of multiple regression $(\beta \mathrm{s})$. All two predictor models showed redundancy, that is the $\beta$ s are somewhat smaller than the corresponding $r$ s due to the shared and overlapping influence of the two predictors that correlated $r=.22, p=.058$, acting in concert. Reflecting the interaction between group, age, and type of mathematics skill noted earlier, group was a stronger predictor of number skills at earlier ages but of arithmetic skills at later ages: the path coefficients decreased with age in magnitude from -.31 to -.26 to -.17 for number skills but increased from -.16 to -.28 to -.41 for arithmetic skills.

Figures 4 and 5 display the mediation models using cognitive functions as the mediators with maternal education as a covariate for number skills and arithmetic skills, respectively. Once mediators were added to the model, the path coefficients for term status declined, becoming inconsequential (<.10 absolute) for number skills and inconsequential, barely small, or small for arithmetic skills at ages 5, 6, and 7, respectively (defining small as .1 to .3 absolute; Cohen, 1988). With age, number skills models accounted for less variance, decreasing from $55 \%$ to $44 \%$ to $39 \%$, whereas arithmetic skills models accounted for more, from $33 \%$ to $32 \%$ to $47 \%$, for ages 5,6 , and 7 , respectively. In sum, the addition of cognitive functions variables to the models rendered the influence of term status inconsequential, indicating that these cognitive functions variables together mediated most of the influence of term status on number and arithmetic skills.

Table 4 provides the statistics for the mediation models. The table shows how the total effect of term status (i.e., its simple correlation with outcome) can be decomposed into the direct effect of term status (i.e., its $\beta$ with cognitive function scores and maternal education in the model); the direct, mediated effects of the cognitive functions (i.e., the product of their 
correlation $[r]$ with term status and their partial standardized regression coefficient $[\beta]$ when term status, other cognitive function scores, and maternal education are included the model); and the direct effect of maternal education (i.e., the product of its $r$ with term status and its $\beta$ when term status and cognitive function scores are included in the model). These direct effects sum to the simple correlation between term status and outcome.

We are now able to ask which particular mediators are noteworthy. One criterion is that both their constituent $r$ and $\beta$ coefficients need to be statistically significant (Baron $\&$ Kenny, 1986). Ten of the 24 mediating effects of the cognitive functions shown Table 4 meet the $p<.05$ for both $r$ and $\beta$ criterion. However, this criterion, like statistical significance, depends on sample size. A criterion based on absolute effect size might be a better choice (Wilkinson, 1999). We suggest viewing mediating effects of .04 or larger as worthy of further consideration. Three additional mediating effects have an effect size larger than .04: One mediating effect with $p<.10$ for the $r$, and $<.05$ for the $\beta$, and two mediating effects with $p<.01$ for the $r$ but was .132 , and .155 for the $\beta$. These 13 mediating effects of cognitive functions are bolded in Table 4 .

The mediator with the largest and most consistent direct effects was Elision; its direct effects averaged .117, were larger for number skills, and decreased with age. For number skills, the absolute effect coefficients accounted for 39\%, 48\%, and 39\% of the total effect at ages 5, 6, and 7 , respectively. VMI accounted for $24 \%$ of the total effect at age 5, and $37 \%$ at age 7 , while the mediating effect was marginal at age 6. The mediating effects of SWM and SST on number skills were small at all time points, though at age $6 \mathrm{SWM}$ had a significant mediating effect of $-.051(16 \%)$. The effect of maternal education on number skills increased over time both in absolute and relative size. Maternal education contributed $12 \%, 20 \%$, and $29 \%$ of the total effect, respectively for ages 5,6 , and 7 . 
In contrast to number skills, the total and direct effect of group on arithmetic skills increased over time. Strikingly, the direct effect of group on arithmetic skills at age 7 accounted for $47 \%$ of the total effect. Like number skills, phonological processing is the strongest mediator among the cognitive functions included in the model. The mediating effect of phonological processing is largest in absolute and relative size at age 5 and decreases over time (their absolute effect coefficients account for 55\%,31\%, and $17 \%$ of the total effect at ages 5, 6, and 7, respectively). Following the same pattern as for number skills, VMI and SST showed mediating effects at age 5 and 7, and SWM at age 6. The effect of maternal education on arithmetic skills accounted for $10-18 \%$ of the total effect of preterm birth.

\section{Sex Effects}

Sex was not included as a variable in the mediation model as the number of boys and girls did not significantly differ between the groups. Nonetheless, to explore sex effects, we reanalyzed the previous trend analyses of number and arithmetic skills including sex as a between-subjects variable. The pattern of male-female differences differed by birth status; group by sex interaction $F(1,74)=4.72$ and $4.24, \eta_{p}^{2}=.060$ and $.054, p=.022$ and .043 , for number and arithmetic skills, respectively. Averaging across the three ages, preterm boys scored lower than girls on number skills (63\% vs. $67 \%)$ and about the same on arithmetic skills (27\% vs. $28 \%$ ). In contrast, full-term boys scored higher than girls on both number (76\% vs. 69\%) and arithmetic skills (46\% vs. $421 \%)$.

We considered whether the group by age interaction described earlier might have been moderated by sex. For number skills the answer is no. The strength of the age by group interaction was moderate and statistically significant, the same as for the numeric skills analysis shown in Table $3 ; \eta_{p}^{2}=.068$ and $.070, p=.023$ and .020 , respectively. But both the age by sex 
and the age by group by sex interactions were small or less in magnitude and not statistically significant; $\eta_{p}^{2}=.016$ and $\sim 0, p=.27$ and .96 , respectively.

The answer is more complex for arithmetic skills. The age by group interaction was statistically significant, the same as for the arithmetic skills analysis shown in Table $3-\eta_{p}^{2}=.20$ and $.18, p=<.001$ for both, respectively. For arithmetic skills, however, both the age by sex and the age by group by sex interactions were moderate and statistically significant $-\eta_{p}^{2}=.072$ and $.11, p=.019$ and .004 , respectively. Follow-up analyses for each sex separately showed that the group by age interaction was statistically significant for boys but not statistically significant in girls $-\eta_{p}^{2}=.45$ and $.015, p=<.001$ and $=.46$, respectively. The mean for boys in arithmetic skills showed divergence, increasing from $16 \%$ to $27 \%$ to $39 \%$ for preterm participants and from $18 \%$ to $36 \%$ to $65 \%$ for full-term participants. Means for girls did not diverge, increasing from $17 \%$ to $25 \%$ to $40 \%$ for preterm and from $18 \%$ to $29 \%$ to $45 \%$ for full-term children.

\section{Discussion}

Preterm birth can have a significant and negative impact on mathematics achievement. Our first aim was to shed light on the impact of preterm birth on two distinct kinds of mathematics skills: number and arithmetic skills. Analyses according to this division showed that there were considerable differences in the developmental trajectories both in the development of these skills per se, and in the development of these skills in preterm and full-term children. Only number and arithmetic skills showed a significant interaction effect of term status and time; this was neither reflected in overall mathematics ability nor in any of the assessed cognitive functions.

The poorer performance of preterm children compared with full-term children in number skills was largest at age 5 and decreased over time. Following preterm birth, children need longer 
to reach the same level of proficiency in number skills compared to children who were born fullterm. That is, the deficit in counting and comparing magnitudes of numbers is not persistent. Instead preterm children are delayed in their development of such skills but eventually "catch up." A qualitatively similar developmental trajectory with a "catch-up" in performance across time has been reported for executive functions and receptive vocabulary in children born preterm (Luu et al., 2009; Ritter, Nelle, Perrig, Steinlin, \& Everts, 2013). To our knowledge, this is the first study of preterm children showing a "catch-up" in number skills performance. Some studies suggest that number skills continue to develop into adolescence (Lyons et al., 2014). Note that the dependent variable in those studies were reaction times rather than accuracy, and the TEMA3 does not measure reaction times. Thus, our findings for a maturing of accuracy measures at age 7 does not contradict potential continued refinement of number skills measured in reaction time. Together, these studies hint towards a maturational delay in various skills following preterm birth. The underlying reason may be maturational delay of brain structures, specifically white matter tracts vulnerable to damage in very preterm birth (Volpe, 2009). In support, MRI studies of preterm children and full-term controls found that brain development in both groups follows a similar trajectory that is delayed for children who were born preterm (Sripada et al., 2018).

In contrast, there was an increase in the performance gap in arithmetic skills with age. Lower arithmetic skills may arise from lower number skills if number skills act as a scaffold to promote learning of arithmetic skills. Perhaps children born very preterm that show a delay in the typical acquisition of number may eventually "catch up" in their arithmetic skills. This seems unlikely. Others have found poorer than expected mathematics achievement among older children and adolescents who were born preterm (Akshoomoff et al., 2017; Litt et al., 2012; Taylor et al., 2009). Similar to our findings, a meta-analysis of 17 studies found that arithmetic 
performance of preterm children and adolescents (6-18 years of age) was 0.71 SD below fullterm controls (Twilhaar, Kieviet, Aarnoudse-Moens, Elburg, \& Oosterlaan, 2018). This hints towards persistent lower performance in complex mathematics skills following preterm birth. A persistent effect of preterm birth on arithmetic skills may be explained by persistent deficits in cognitive functions that contribute to these skills.

Our second aim sought to identify the specific cognitive functions that mediate number and arithmetic skills as children move from preschool through first grade. We used a mediation model, testing for the potentially mediating effect of spatial working memory, inhibitory control, visual-motor integration, and phonological processing. The assessment of the variety of skills, and analysis via multiple mediation models has several advantages: indirect effects of variables can be compared in the context of others, the direct effect of group can be determined, and the parameter estimation is more accurate. Importantly, theoretical causality drives mediation models, but does not provide proof of causality. The direction of influence here was determined by using non-academic cognitive functions (spatial working memory, inhibitory control, phonological processing, visual-motor integration) as mediators of the mathematics skills. The structure of our mediation models are in line with our previous study of 5-year old children born preterm (Hasler \& Akshoomoff, 2019) and studies of children with spina bifida (Barnes et al., 2014; Raghubar et al., 2015).

Phonological processing was the strongest mediator for both number skills and arithmetic skills. This is consistent with previous studies showing the effect of early phonological skills on mathematics performance. Phonological awareness in preschool and kindergarten has been reported to be predictive of several distinct mathematics skills, including numeration and calculation (LeFevre et al., 2010). Phonological awareness has also been associated with 
arithmetic skills in older children (De Smedt et al., 2010), and shown to mediate the relationship between other developmental disorders (spina bifida) and calculation skills (Barnes et al., 2014). This strong association may be explained by a shared network of brain regions associated with both phonological processing and mathematics skills. The temporo-parietal cortex, specifically the arcuate fasciculus are candidate regions. For example, Van Beek, Ghesquière, Lagae, \& De Smedt (2014) found a correlation between the arcuate fasciculus microstructure and children's addition/multiplication skills. These effects disappear when covarying for phonological processing, pointing towards an involvement of phonological processing when solving mathematics problems.

In line with previous research, we found that visual-motor integration measured by the Beery VMI, was a strong mediator for both types of mathematics skills at age 5 and age 7. Performance on the VMI has been associated with mathematics skills in children at age 4 (Verdine, Irwin, Golinkoff, \& Hirsh-Pasek, 2014), and 5-18 years (Carlson, Rowe, \& Curby, 2013). This link has rarely been investigated in children born preterm. Perez-Roche et al. (2016) found an effect of visual abilities on school performance in small for gestational age children (though school performance was assessed with a parent questionnaire). Others have found a link between low motor and visuospatial function and low academic achievement in extremely preterm children (Marlow, Hennessy, Bracewell, \& Wolke, 2007).

Inhibitory control had a mediating effect on arithmetic skills at age 7 . In line with these findings, inhibitory control has been reported to be associated with procedural arithmetic skills in children and conceptual knowledge in adults (Gilmore, Keeble, Richardson, \& Cragg, 2015). Inhibitory control has also been shown to be predictive of early mathematics skills in 3-5 year old children (Blair \& Razza, 2007) and of arithmetic skills in fourth graders (Passolunghi \& 
Siegel, 2001). However, these studies investigated the role of inhibition on mathematics in the absence of other cognitive functions, which is likely to account for different results.

The participants in the full-term group had higher maternal education than the preterm group. This may be due to them being a convenience sample. However, this might also be a closer representation of the true distribution of maternal education in the preterm and full-term population (Behrman \& Butler, 2007; Thompson, Irgens, Rasmussen, \& Daltveit, 2006). Higher maternal education has been linked to better mathematics and reading performance, fewer behavioral problems, and less grade repetition (Carneiro, Meghir, \& Parey, 2013; ElHassan et al., 2018). We included maternal education in the mediation model and, as expected, higher maternal education showed a significant positive effect on both number and arithmetic skills.

One might expect that the influence of social variables, such as maternal education, on mathematics would increase over time, and conversely that the influence of biological variables associated with prematurity would decrease. However, in a study of extremely preterm children 8 and 18 years of age, Doyle et al. (2015) found that the adverse effect of preterm birth persists over time. In line with their results, we found that the effect of group on arithmetic skills increased over time. Interestingly, not only the total effect of preterm birth, but also the direct effect increases from age 5 years to 7 years. In fact, at age 7 years only about half of the total effect of preterm birth on arithmetic skills was mediated by other cognitive functions. In contrast, the direct effect of preterm birth on number skills was statistically non-significant at all three time points, meaning the total effect of preterm birth was fully mediated by cognitive functions (mainly phonological processing and visual-motor integration).

In addition, at age 7, we found an interaction effect of sex and group, with males having significantly higher arithmetic skills scores than females in the full-term group only. There is a 
vast body of literature on gender differences and learning and education. Studies have shown that teachers' implicit gender bias affects achievement in children, and that children themselves develop gender stereotypes of males being "smarter" and "better in math" already in elementary school (Bian, Leslie, \& Cimpian, 2017; Cvencek, Meltzoff, \& Greenwald, 2011; Lavy \& Sand, 2015). One possible explanation as to why we did not observe this effect in the preterm group might be that the differences in cognitive processing related to preterm birth do not effectively influence preterm males; that is, societal and cultural influences do not impact preterm children in the same way as full-term children. On the other hand, it might be that these influences are delayed in preterm children and may become evident later in their educational development.

A significant takeaway message from this study is that our healthy preterm children showed reliable adverse effects of preterm birth. Although severity of neonatal brain pathology is linked to cognitive outcomes in preterm children (Murray et al., 2014), preterm children on the healthy end of the continuum still show significant cognitive disparities that negatively impact their academic performance. The lack of severe disabilities is not an indication of typical developmental outcomes and any child born preterm requires assessment before formal education begins, with continued monitoring.

\section{Conclusion}

Inclusion of a broad variety of cognitive functions distinguishes this study and provides an important contribution to the literature. Previous work on the effect of cognitive functions on mathematics skills have primarily focused on functions within a single cognitive domain. Cognitive functions and academic skills in children develop dynamically between ages 5 and 7 and change in complexity. Our study gives valuable insight into how these skills are impacted by preterm birth and the contribution of cognitive functions on mathematics skills in both full-term 
and preterm birth children. Neuropsychological assessment of preterm children at 5 years of age has been shown to be predictive of cognitive functions and need for educational support at age 11 (Lind, Nyman, Lehtonen, \& Haataja, 2019). Hence, the cognitive functions investigated here, particularly phonological processing, can be neuropsychological markers for early evaluation of children with increased risk for difficulties in mathematics.

\section{Acknowledgments}

The Eunice Kennedy Shriver National Institute of Child Health and Human Development grant R01HD075765 supported this work. We thank the children and families who participated in this study. Thank you to Holly Hasler, Ph.D., Stephanie Torres, M.A., Kelly McPherson, Akshita Taneja, and Rubaina Dang; and our collaborators: Martha Fuller, Ph.D., PPCNP-BC, Yvonne Vaucher, M.D., Terry Jernigan, Ph.D., and Joan Stiles, Ph.D.

\section{Disclosure of Interest}

The authors report no conflict of interest.

\section{Data Availability Statement}

The data supporting the findings of this study are available from Dr. Natacha Akshoomoff (nakshoomoff@ucsd.edu) upon reasonable request. 


\section{References}

Aarnoudse-Moens, C. S. H., Oosterlaan, J., Duivenvoorden, H. J., van Goudoever, J. B., \& Weisglas-Kuperus, N. (2011). Development of preschool and academic skills in children born very preterm. The Journal of Pediatrics, 158(1), 51-56.

https://doi.org/10.1016/j.jpeds.2010.06.052

Akshoomoff, N., Joseph, R. M., Taylor, H. G., Allred, E. N., Heeren, T., O’Shea, T. M., \& Kuban, K. C. K. (2017). Academic achievement deficits and their neuropsychological correlates in children born extremely preterm. Journal of Developmental and Behavioral Pediatrics : JDBP, 38(8), 627-637. https://doi.org/10.1097/DBP.0000000000000479

Anderson, P. J. (2014). Neuropsychological outcomes of children born very preterm. Seminars in Fetal and Neonatal Medicine, 19(2), 90-96. https://doi.org/10.1016/j.siny.2013.11.012

Barnes, M. A., Raghubar, K. P., English, L., Williams, J. M., Taylor, H., \& Landry, S. (2014). Longitudinal mediators of achievement in mathematics and reading in typical and atypical development. Journal of Experimental Child Psychology, 119, 1-16. https://doi.org/10.1016/j.jecp.2013.09.006

Baron, R. M., \& Kenny, D. A. (1986). The moderator-mediator variable distinction in social psychological research: Conceptual, strategic, and statistical considerations. Journal of Personality and Social Psychology, 51(6), 1173-1182.

Basten, M., Jaekel, J., Johnson, S., Gilmore, C., \& Wolke, D. (2015). Preterm birth and adult wealth: mathematics skills count. Psychological Science, 26(10), 1608-1619

Beery, K. E. (2004). Beery VMI: The Beery-Buktenica developmental test of visual-motor integration. Minneapolis, MN: Pearson. 
Behrman, R., \& Butler, A. (2007). Preterm Birth: Causes, Consequences, and Prevention. National Academies Press.

Bian, L., Leslie, S.-J., \& Cimpian, A. (2017). Gender stereotypes about intellectual ability emerge early and influence children's interests. Science, 355(6323), 389-391. https://doi.org/10.1126/science.aah6524

Blair, C., \& Razza, R. P. (2007). Relating effortful control, executive function, and false belief understanding to emerging math and literacy ability in k indergarten. Child Development, 78(2), 647-663. https://doi.org/10.1111/j.1467-8624.2007.01019.x

Bull, R., \& Lee, K. (2014). Executive functioning and mathematics achievement. Child Development Perspectives, 8(1), 36-41. https://doi.org/10.1111/cdep.12059

CANTAB® Cognitive assessment software. (2017). Cambridge, UK: Cambridge Cognition.

Carlson, A. G., Rowe, E., \& Curby, T. W. (2013). Disentangling fine motor skills' relations to academic achievement: The relative contributions of visual-spatial integration and visualmotor coordination. The Journal of Genetic Psychology, 174(5), 514-533. https://doi.org/10.1080/00221325.2012.717122

Carneiro, P., Meghir, C., \& Parey, M. (2013). Maternal education, home environments, and the development of children and adolescents. Journal of the European Economic Association, 11(suppl_1), 123-160. https://doi.org/10.1111/j.1542-4774.2012.01096.x

Cohen, J. (1988). Statistical Power Analyses for the Behavioral Sciences (2nd Ed.). Hillsdale, NJ: Lawrence Erlbaum Associates.

Chawanpaiboon, S., Vogel, J. P., Moller, A.-B., Lumbiganon, P., Petzold, M., Hogan, D., ... Gülmezoglu, A. M. (2019). Global, regional, and national estimates of levels of preterm 
birth in 2014: A systematic review and modelling analysis. The Lancet Global Health, 7(1), e37-e46. https://doi.org/10.1016/S2214-109X(18)30451-0

Cvencek, D., Meltzoff, A. N., \& Greenwald, A. G. (2011). Math-gender stereotypes in elementary school children. Child Development, 82(3), 766-779. https://doi.org/10.1111/j.1467-8624.2010.01529.x

De Smedt, B., Taylor, J., Archibald, L., \& Ansari, D. (2010). How is phonological processing related to individual differences in children's arithmetic skills? Developmental Science, 13(3), 508-520. https://doi.org/10.1111/j.1467-7687.2009.00897.x

Doyle, L. W., Cheong, J. L. Y., Burnett, A., Roberts, G., Lee, K. J., Anderson, P. J., \& Victorian Infant Collaborative Study Group. (2015). Biological and social influences on outcomes of extreme-preterm/low-birth weight adolescents. Pediatrics, 136(6), e1513-1520. https://doi.org/10.1542/peds.2015-2006

Duncan, G. J., Dowsett, C. J., Claessens, A., Magnuson, K., Huston, A. C., Klebanov, P., ... Japel, C. (2007). School readiness and later achievement. Developmental Psychology, 43(6), 1428-1446. https://doi.org/10.1037/0012-1649.43.6.1428

ElHassan, N. O., Bai, S., Gibson, N., Holland, G., Robbins, J. M., \& Kaiser, J. R. (2018). The impact of prematurity and maternal socioeconomic status and education level on achievement-test scores up to 8th grade. PLOS ONE, 13(5). https://doi.org/10.1371/journal.pone.0198083

Fuhs, M. W., \& McNeil, N. M. (2013). ANS acuity and mathematics ability in preschoolers from low-income homes: Contributions of inhibitory control. Developmental Science, 16(1), 136-148. https://doi.org/10.1111/desc.12013 
Geary, D. C., \& Moore, A. M. (2016). Cognitive and brain systems underlying early mathematical development. In M. Cappelletti \& W. Fias (Eds.), Progress in Brain Research (Vol. 227, pp. 75-103). Elsevier. https://doi.org/10.1016/bs.pbr.2016.03.008

Geldof, C. J. A., van Wassenaer, A. G., de Kieviet, J. F., Kok, J. H., \& Oosterlaan, J. (2012). Visual perception and visual-motor integration in very preterm and/or very low birth weight children: A meta-analysis. Research in Developmental Disabilities, 33(2), 726736. https://doi.org/10.1016/j.ridd.2011.08.025

Gilmore, C., Keeble, S., Richardson, S., \& Cragg, L. (2015). The role of cognitive inhibition in different components of arithmetic. ZDM, 47(5), 771-782. https://doi.org/10.1007/s11858-014-0659-y

Ginsburg, H., \& Baroody, A. J. (2003). TEMA-3: Test of early mathematics ability. Pro-Ed.

Grytten, J., Monkerud, L., Skau, I., Eskild, A., Sørensen, R. J., \& Saugstad, O. D. (2017). Saving newborn babies - The benefits of interventions in neonatal care in Norway over more than 40 years. Health Economics, 26(3), 352-370. https://doi.org/10.1002/hec.3314

Hasler, H. M., \& Akshoomoff, N. (2019). Mathematics ability and related skills in preschoolers born very preterm. Child Neuropsychology, 25(2), 162-178. https://doi.org/10.1080/09297049.2017.1412413

Hasler, H. M., Brown, T. T., \& Akshoomoff, N. (2020). Variations in brain morphometry among healthy preschoolers born very preterm. Early Human Development, 140, 104929

Johnson, S., Wolke, D., Hennessy, E., \& Marlow, N. (2011). Educational outcomes in extremely preterm children: Neuropsychological correlates and predictors of attainment. Developmental Neuropsychology, 36(1), 74-95. https://doi.org/10.1080/87565641.2011.540541 
Jordan, J.-A., Wylie, J., \& Mulhern, G. (2010). Phonological awareness and mathematical difficulty: A longitudinal perspective. British Journal of Developmental Psychology, 28(1), 89-107. https://doi.org/10.1348/026151010X485197

Kull, M. A., \& Coley, R. L. (2015). Early physical health conditions and school readiness skills in a prospective birth cohort of U.S. children. Social Science \& Medicine, 142, 145-153. https://doi.org/10.1016/j.socscimed.2015.08.030

Kulp, M. T. (1999). Relationship between visual motor integration skill and academic performance in kindergarten through third grade. Optometry and Vision Science, 76(3), $159-163$.

Lan, X., Legare, C. H., Ponitz, C. C., Li, S., \& Morrison, F. J. (2011). Investigating the links between the subcomponents of executive function and academic achievement: A crosscultural analysis of Chinese and American preschoolers. Journal of Experimental Child Psychology, 108(3), 677-692. https://doi.org/10.1016/j.jecp.2010.11.001

Lavy, V., \& Sand, E. (2015). On The Origins of Gender Human Capital Gaps: Short and Long Term Consequences of Teachers' Stereotypical Biases (Working Paper No. 20909). https://doi.org/10.3386/w20909

LeFevre, J.-A., Fast, L., Skwarchuk, S.-L., Smith-Chant, B. L., Bisanz, J., Kamawar, D., \& Penner-Wilger, M. (2010). Pathways to mathematics: Longitudinal predictors of performance. Child Development, 81(6), 1753-1767. https://doi.org/10.1111/j.14678624.2010.01508.x

Libertus, M. E., Feigenson, L., \& Halberda, J. (2013). Numerical approximation abilities correlate with and predict informal but not formal mathematics abilities. Journal of 
Experimental Child Psychology, 116(4), 829-838.

https://doi.org/10.1016/j.jecp.2013.08.003

Lind, A., Nyman, A., Lehtonen, L., \& Haataja, L. (2019). Predictive value of psychological assessment at five years of age in the long-term follow-up of very preterm children. Child Neuropsychology, O(0), 1-12. https://doi.org/10.1080/09297049.2019.1674267

Litt, J. S., Taylor, H. G., Margevicius, S., Schluchter, M., Andreias, L., \& Hack, M. (2012). Academic achievement of adolescents born with extremely low birth weight. Acta Paediatrica, 101(12), 1240-1245. https://doi.org/10.1111/j.1651-2227.2012.02790.x

Loe, I. M., Feldman, H. M., \& Huffman, L. C. (2014). Executive function mediates effects of gestational age on functional outcomes and behavior in preschoolers. Journal of Developmental and Behavioral Pediatrics : JDBP, 35(5), 323-333. https://doi.org/10.1097/DBP.0000000000000063

Løhaugen, G. C. C., Gramstad, A., Evensen, K. A. I., Martinussen, M., Lindqvist, S., Indredavik, M., ... Skranes, J. (2010). Cognitive profile in young adults born preterm at very low birthweight. Developmental Medicine \& Child Neurology, 52(12), 1133-1138. https://doi.org/10.1111/j.1469-8749.2010.03743.x

Luu, T. M., Ment, L. R., Schneider, K. C., Katz, K. H., Allan, W. C., \& R.Vohr, B. (2009). Lasting effects of preterm birth and neonatal brain hemorrhage at 12 years of age. Pediatrics, 123(3), 1037-1044. https://doi.org/10.1542/peds.2008-1162

Lyons, I. M., Price, G. R., Vaessen, A., Blomert, L., \& Ansari, D. (2014). Numerical predictors of arithmetic success in grades 1-6. Developmental Science, 17(5), 714-726. https://doi.org/10.1111/desc.12152 
Marlow, N., Hennessy, E. M., Bracewell, M. A., \& Wolke, D. (2007). Motor and executive function at 6 years of age after extremely preterm birth. Pediatrics, 120(4), 793-804. https://doi.org/10.1542/peds.2007-0440

Mazzocco, M. M. M., Feigenson, L., \& Halberda, J. (2011). Preschoolers' precision of the Approximate Number System predicts later school mathematics performance. PLOS ONE, 6(9), e23749. https://doi.org/10.1371/journal.pone.0023749

Mulder, H., Pitchford, N. J., \& Marlow, N. (2010). Processing speed and working memory underlie academic attainment in very preterm children. Archives of Disease in Childhood - Fetal and Neonatal Edition, 95(4), F267-F272.

https://doi.org/10.1136/adc.2009.167965

Murray, A. L., Scratch, S. E., Thompson, D. K., Inder, T. E., Doyle, L. W., Anderson, J. F. I., \& Anderson, P. J. (2014). Neonatal brain pathology predicts adverse attention and processing speed outcomes in very preterm and/or very low birth weight children. Neuropsychology, 28(4), 552-562. https://doi.org/10.1037/neu0000071

Passolunghi, M. C., \& Siegel, L. S. (2001). Short-term memory, working memory, and inhibitory control in children with difficulties in arithmetic problem solving. Journal of Experimental Child Psychology, 80(1), 44-57. https://doi.org/10.1006/jecp.2000.2626

Perez-Roche, T., Altemir, I., Giménez, G., Prieto, E., González, I., Peña-Segura, J. L., ... Pueyo, V. (2016). Effect of prematurity and low birth weight in visual abilities and school performance. Research in Developmental Disabilities, 59, 451-457. https://doi.org/10.1016/j.ridd.2016.10.002 
Pritchard, V. E., Clark, C. A. C., Liberty, K., Champion, P. R., Wilson, K., \& Woodward, L. J. (2009). Early school-based learning difficulties in children born very preterm. Early Human Development, 85(4), 215-224. https://doi.org/10.1016/j.earlhumdev.2008.10.004

Raghubar, K. P., Barnes, M. A., Dennis, M., Cirino, P. T., Taylor, H., \& Landry, S. (2015). Neurocognitive predictors of mathematical processing in school-aged children with spina bifida and their typically developing peers: Attention, working memory, and fine motor skills. Neuropsychology, 29(6), 861-873. https://doi.org/10.1037/neu0000196

Ramachandrappa, A., \& Jain, L. (2009). Health issues of the late preterm infant. Pediatric Clinics, 56(3), 565-577. https://doi.org/10.1016/j.pcl.2009.03.009

Ribner, A. D., Willoughby, M. T., \& Blair, C. B. (2017). Executive function buffers the association between early math and later academic skills. Frontiers in Psychology, 8. https://doi.org/10.3389/fpsyg.2017.00869

Ritter, B. C., Nelle, M., Perrig, W., Steinlin, M., \& Everts, R. (2013). Executive functions of children born very preterm-Deficit or delay? European Journal of Pediatrics, 172(4), 473-483. https://doi.org/10.1007/s00431-012-1906-2

Rose, S. A., Feldman, J. F., \& Jankowski, J. J. (2011). Modeling a cascade of effects: The role of speed and executive functioning in preterm/full-term differences in academic achievement. Developmental Science, 14(5), 1161-1175. https://doi.org/10.1111/j.14677687.2011.01068.x

Ryoo, J. H., Molfese, V. J., Brown, E. T., Karp, K. S., Welch, G. W., \& Bovaird, J. A. (2015). Examining factor structures on the Test of Early Mathematics Ability - 3: A longitudinal approach. Learning and Individual Differences, 41, 21-29. https://doi.org/10.1016/j.lindif.2015.06.003 
Schneider, M., Beeres, K., Coban, L., Merz, S., Schmidt, S. S., Stricker, J., \& Smedt, B. D. (2017). Associations of non-symbolic and symbolic numerical magnitude processing with mathematical competence: A meta-analysis. Developmental Science, 20(3), e12372. https://doi.org/10.1111/desc.12372

Sortor, J., \& Kulp, and M. (2003). Are the results of the Beery-Buktenica developmental test of visual-motor integration and its subtests related to achievement test scores? Optometry and Vision Science, 80(11), 758-763.

Sripada, K., Bjuland, K. J., Sølsnes, A. E., Håberg, A. K., Grunewaldt, K. H., Løhaugen, G. C., ... Skranes, J. (2018). Trajectories of brain development in school-age children born preterm with very low birth weight. Scientific Reports, 8(1), 15553. https://doi.org/10.1038/s41598-018-33530-8

Tatsuoka, C., McGowan, B., Yamada, T., Espy, K. A., Minich, N., \& Taylor, H. G. (2016). Effects of extreme prematurity on numerical skills and executive function in kindergarten children: An application of partially ordered classification modeling. Learning and Individual Differences, 49, 332-340. https://doi.org/10.1016/j.lindif.2016.05.002

Taylor, H. G., Espy, K. A., \& Anderson, P. J. (2009). Mathematics deficiencies in children with very low birth weight or very preterm birth. Developmental Disabilities Research Reviews, 15(1), 52-59. https://doi.org/10.1002/ddrr.51

Taylor, H. G., Klein, N., Espy, K. A., Schluchter, M., Minich, N., Stilp, R., \& Hack, M. (2018). Effects of extreme prematurity and kindergarten neuropsychological skills on early academic progress. Neuropsychology, 32(7), 809-821. https://doi.org/10.1037/neu0000434 
Thompson, J. M. D., Irgens, L. M., Rasmussen, S., \& Daltveit, A. K. (2006). Secular trends in socio-economic status and the implications for preterm birth. Paediatric and Perinatal Epidemiology, 20(3), 182-187. https://doi.org/10.1111/j.1365-3016.2006.00711.x

Tukey, JW. (1977). Exploratory Data Analysis. NY: Addison-Wesley.

Twilhaar, E. S., Kieviet, J. F. de, Aarnoudse-Moens, C. S., Elburg, R. M. van, \& Oosterlaan, J. (2018). Academic performance of children born preterm: A meta-analysis and metaregression. Archives of Disease in Childhood - Fetal and Neonatal Edition, 103(4), F322-F330. https://doi.org/10.1136/archdischild-2017-312916

Van Beek, L., Ghesquière, P., Lagae, L., \& De Smedt, B. (2014). Left fronto-parietal white matter correlates with individual differences in children's ability to solve additions and multiplications: A tractography study. NeuroImage, 90, 117-127. https://doi.org/10.1016/j.neuroimage.2013.12.030

van Veen, S., van Wassenaer-Leemhuis, A. G., van Kaam, A. H., Oosterlaan, J., \& AarnoudseMoens, C. S. H. (2019). Visual perceptive skills account for very preterm children's mathematical difficulties in preschool. Early Human Development, 129, 11-15. https://doi.org/10.1016/j.earlhumdev.2018.12.018

Verdine, B. N., Irwin, C. M., Golinkoff, R. M., \& Hirsh-Pasek, K. (2014). Contributions of executive function and spatial skills to preschool mathematics achievement. Journal of Experimental Child Psychology, 126, 37-51. https://doi.org/10.1016/j.jecp.2014.02.012

Vohr, B. (2014). Speech and language outcomes of very preterm infants. Seminars in Fetal and Neonatal Medicine, 19(2), 78-83. https://doi.org/10.1016/j.siny.2013.10.007 
Volpe, J. J. (2009). Brain injury in premature infants: A complex amalgam of destructive and developmental disturbances. The Lancet Neurology, 8(1), 110-124. https://doi.org/10.1016/S1474-4422(08)70294-1

Wagner, R. K., Torgesen, J. K., Rashotte, C. A., \& Pearson, N. A. (2013). Comprehensive Test of Phonological Processing-2nd Ed. (CTOPP-2). San Antonio, TX: Psychological Corporation.

Wilkinson, L. (1999). Task Force on Statistical Inference, American Psychological Association, Science Directorate. Statistical methods in psychology journals: Guidelines and explanations. American Psychologist, 54(8), 594-604.

Woodcock, R., McGrew, K., \& Mather, N. (2007). Woodcock Johnson III Normative Update Tests of Achievement. Rolling Meadows, IL: Riverside Publishing. 
bioRxiv preprint doi: https://doi.org/10.1101/868547; this version posted April 18,2020 . The copyright holder for this preprint (which was not certified by peer review) is the author/funder, who has granted bioRxiv a license to display the preprint in perpetuity. It is made available under aCC-BY-NC-ND 4.0 International license.

MATHEMATICS SKILLS IN PRETERM CHILDREN

Table 1

Definition of Number Skills and Arithmetic Skills

\begin{tabular}{|c|c|c|c|}
\hline & Category+ & \# items & Type of task \\
\hline \multirow{3}{*}{$\begin{array}{l}\text { Number } \\
\text { Skills }\end{array}$} & Verbal Counting & 14 & Counting until a certain number; tell the successor number \\
\hline & Counting Objects & 7 & Counting objects \\
\hline & $\begin{array}{l}\text { Numerical } \\
\text { Comparison }\end{array}$ & 7 & $\begin{array}{l}\text { Which number is more; which number is closer to a third } \\
\text { number }\end{array}$ \\
\hline \multirow{3}{*}{$\begin{array}{l}\text { Arithmetic } \\
\text { Skills }\end{array}$} & Set Construction & 9 & Division problems presented in story/money form \\
\hline & Calculation & 18 & Calculation problems presented in story form or abstract \\
\hline & Number Facts & 9 & Single digits addition (verbal, no story form, with time limit) \\
\hline Not included & Numeral Literacy & 8 & Reading \& writing numerals \\
\hline
\end{tabular}

Note. Number skills are measured by TEMA-3 test items that require ordering of numbers by magnitude. Arithmetic skills are measured through TEMA-3 test items that require manipulation of numbers.

†Category as defined by Ryoo et al. (2015) 
MATHEMATICS SKILLS IN PRETERM CHILDREN

\section{Table 2}

Participant characteristics

\begin{tabular}{|c|c|c|c|}
\hline & $\begin{array}{l}\text { Preterm } \\
\mathrm{n}=51\end{array}$ & $\begin{array}{l}\text { Full-term } \\
n=27\end{array}$ & $\begin{array}{c}\text { Effect size } \\
\text { (Test statistic, p-value) }\end{array}$ \\
\hline $\begin{array}{l}\text { GA at birth in weeks } \\
\text { mean (SD, min-max) }\end{array}$ & $\begin{array}{c}29.4 \\
(2.00,25-32)\end{array}$ & $\begin{array}{c}39.7 \\
(0.77,38-41)\end{array}$ & $\begin{array}{c}\eta_{2}=.894 \\
(\mathrm{~F}=643, p<.001)\end{array}$ \\
\hline $\begin{array}{l}\text { Birth weight in g } \\
\text { mean (SD, min-max) }\end{array}$ & $\begin{array}{c}1327 \\
(439,680-2410)\end{array}$ & $\begin{array}{c}3410 \\
(561,2353-4422)\end{array}$ & $\begin{array}{c}\eta_{2}=.806 \\
(\mathrm{~F}=316, p<.001)\end{array}$ \\
\hline Sex (female) & $47 \%$ & $48 \%$ & $\mathrm{~V}=.010\left(\chi_{2}=.008, p=.927\right)$ \\
\hline \multicolumn{4}{|l|}{ Age at testing: mean (SD) } \\
\hline Time 1 (Age 5) & $5.3(0.3)$ & $5.4(0.3)$ & $\eta_{2}=.018(\mathrm{~F}=1.37, p=.245)$ \\
\hline Time 2 (Age 6) & $6.4(0.4)$ & $6.4(0.3)$ & $\eta_{2}=.006(F=.421, p=.518)$ \\
\hline Time 3 (Age 7) & $7.3(0.4)$ & $7.4(0.3)$ & $\eta_{2}=.005(\mathrm{~F}=.420, p=.519)$ \\
\hline \multicolumn{4}{|l|}{$\begin{array}{l}\text { Maternal education } \\
\text { absolute (relative frequency) }\end{array}$} \\
\hline 1) high school degree & $7-14 \%$ & $3-10 \%$ & $\eta_{2}=.048$ \\
\hline 2) 1-3 year college & $18-35 \%$ & $6-21 \%$ & $(\mathrm{U}=514, p=.055)$ \\
\hline 3) college degree & $21-41 \%$ & $10-35 \%$ & \\
\hline 4) graduate degree & $5-10 \%$ & $10-35 \%$ & \\
\hline \multicolumn{4}{|l|}{$\begin{array}{l}\text { Household income: } \\
\text { absolute (relative frequency) }\end{array}$} \\
\hline 1) below $\$ 50,000$ & $8-16 \%$ & $1-3 \%$ & $\eta_{2}=.002$ \\
\hline 2) $\$ 50,000-<\$ 100,000$ & $16-31 \%$ & $13-45 \%$ & $(\mathrm{U}=621, p=.736)$ \\
\hline 3) $\$ 100,000-<\$ 200,000$ & $18-35 \%$ & $13-45 \%$ & \\
\hline 4) $\$ 200,000$ and above & $8-16 \%$ & $1-3 \%$ & \\
\hline Missing information & $1-2 \%$ & $1-3 \%$ & \\
\hline \multicolumn{4}{|l|}{ Race } \\
\hline African American & $1-2 \%$ & $0-0 \%$ & $V=.281$ \\
\hline Asian & $2-4 \%$ & $4-15 \%$ & $\left(\chi_{2}=6.15, p=.188\right)$ \\
\hline Caucasian & $40-78 \%$ & $16-59 \%$ & \\
\hline Mixed/other & $7-14 \%$ & $7-26 \%$ & \\
\hline Missing information & $1-2 \%$ & $0-0 \%$ & \\
\hline Ethnicity (Hispanic/Latinx) & $19-37 \%$ & $8-30 \%$ & $V=.28\left(\chi_{2}=.454, p=.501\right)$ \\
\hline
\end{tabular}

Note. Group comparisons were performed via ANOVA F[1,77], effect size: partial $\eta_{2}$ for GA at birth, birth weight, and age at testing; via Mann-Whitney U test, effect size: $\eta_{2}$ for maternal education, and household income; and via Chi-square test, effect size: Cramer's V for sex, race, and ethnicity. GA: gestational age; g: grams.. 
bioRxiv preprint doi: https://doi.org/10.1101/868547; this version posted April 18, 2020. The copyright holder for this preprint (which was not certified by peer review) is the author/funder, who has granted bioRxiv a license to display the preprint in perpetuity. It is made available under aCC-BY-NC-ND 4.0 International license.

MATHEMATICS SKILLS IN PRETERM CHILDREN

Table 3

Analysis of Covariance Results for Mathematic Ability and Cognitive Function Scores

\begin{tabular}{lcccccc}
\hline & \multicolumn{2}{c}{ Group (PT/FT) } & \multicolumn{2}{c}{ Age } & \multicolumn{2}{c}{ Age × Group } \\
\cline { 2 - 7 } Variable & $\eta^{2}$ & $p$ & $\eta^{2}$ & $p$ & $\eta^{2}$ & $p$ \\
\hline Mathematics scores & & & & & & \\
TEMA-3 overall (scaled) & .076 & .015 & .031 & .39 & .042 & .074 \\
TEMA-3 overall (\%) & .113 & .003 & .429 & $<.001$ & .005 & .543 \\
Number skills (\%) & .104 & .004 & .425 & $<.001$ & .070 & .020 \\
Arithmetic skills (\%) & .145 & .001 & .194 & $<.001$ & .180 & $<.001$ \\
Cognitive function scores & & & & & & \\
SWM (inverse) & .030 & .135 & .172 & $<.001$ & .004 & .609 \\
SST (inverse log) & .096 & .006 & .126 & .002 & $<.001$ & .940 \\
VMI & .229 & $<.001$ & .214 & $<.001$ & .001 & .821 \\
Elision & .139 & .001 & .378 & $<.001$ & .001 & .886 \\
\hline
\end{tabular}

Note. Group, $n=78$ (51 preterm, 27 full-term). Results are for repeated measures ANCOVA with age (5, 6, and 7 years) as the repeated measure, group as the between-groups factor (PT vs. FT), and maternal education as the covariate. PT: preterm, FT: full-term, TEMA-3: Test for Early Mathematics Ability, 3rd edition, SWM: Spatial Working Memory; SST: Stop Signal Task; VMI: Visual-motor Integration. 
bioRxiv preprint doi: https://doi.org/10.1101/868547; this version posted April 18,2020 . The copyright holder for this preprint (which was not certified by peer review) is the author/funder, who has granted bioRxiv a license to display the preprint in perpetuity. It is made available under aCC-BY-NC-ND 4.0 International license.

MATHEMATICS SKILLS IN PRETERM CHILDREN

Table 4

Mediation Analysis Results for Cognitive Function Scores

\begin{tabular}{|c|c|c|c|c|c|c|c|c|c|}
\hline & \multicolumn{3}{|c|}{ Age 5} & \multicolumn{3}{|c|}{ Age 6} & \multicolumn{3}{|c|}{ Age 7} \\
\hline & $\begin{array}{l}\text { r with } \\
\text { PT/FT }\end{array}$ & $\begin{array}{l}\text { std. } \beta \\
\text { for skill }\end{array}$ & $\begin{array}{c}\text { effect } \\
\text { coefficient }\end{array}$ & $\begin{array}{l}\text { r with } \\
\text { PT/FT }\end{array}$ & $\begin{array}{l}\text { std. } \beta \\
\text { for skill }\end{array}$ & $\begin{array}{c}\text { effect } \\
\text { coefficient }\end{array}$ & $\begin{array}{l}\text { r with } \\
\text { PT/FT }\end{array}$ & $\begin{array}{l}\text { std. } \beta \\
\text { for skill }\end{array}$ & $\begin{array}{c}\text { effect } \\
\text { coefficient }\end{array}$ \\
\hline \multicolumn{10}{|c|}{ Number Skills } \\
\hline Group & & & $-.061(16 \%)$ & & & $-.048(15 \%)$ & & & $.032(-13 \%)$ \\
\hline SWM & -.08 & .03 & $-.002(.5 \%)$ & $-.23 *$ & $.22 *$ & $-.051(16 \%)$ & -.09 & $.21 *$ & -.019 (7.5\%) \\
\hline SST & $-.22+$ & .14 & $-.031(8.2 \%)$ & $-.26^{*}$ & .07 & $-.018(5.5 \%)$ & $-.22+$ & .02 & $-.004(1.6 \%)$ \\
\hline VMI & $-.43 * *$ & $.21^{*}$ & $-.090(24 \%)$ & $-.29 *$ & -.02 & $.006(-1.8 \%)$ & $-.40 * *$ & $.23^{*}$ & $-.092(37 \%)$ \\
\hline Elision & $-.37 * *$ & $.40 * *$ & .148 (39\%) & $-.34 * *$ & $.46 * *$ & $-.156(48 \%)$ & $-.35^{* *}$ & $.28^{*}$ & $-.098(39 \%)$ \\
\hline M.Ed. & $-.22+$ & $.21 *$ & $.046(12 \%)$ & $-.22+$ & $.29 * *$ & $-.064(20 \%)$ & $-.22+$ & $.33 * *$ & $-.073(29 \%)$ \\
\hline Total & & & -.378 & & & .327 & & & .252 \\
\hline \multicolumn{10}{|c|}{ Arithmetic skills } \\
\hline Group & & & $.050(-24 \%)$ & & & $-.119(35 \%)$ & & & $-.219(47 \%)$ \\
\hline SWM & -.08 & .10 & $-.008(3.8 \%)$ & $-.23 *$ & $.24^{*}$ & $-.055(16 \%)$ & -.09 & .16 & $-.014(3.0 \%)$ \\
\hline SST & $-.22+$ & .11 & $-.024(11 \%)$ & $-.26^{*}$ & .05 & $-.013(3.8 \%)$ & $-.22+$ & $.22^{*}$ & $-.048(10 \%)$ \\
\hline VMI & $-.43 * *$ & .18 & $-.077(36 \%)$ & $-.29 *$ & -.04 & $.012(-3.6 \%)$ & $-.40 * *$ & .14 & $-.056(12 \%)$ \\
\hline Elision & $-.37 * *$ & $.31 *$ & $-.115(55 \%)$ & $-.34 * *$ & $.31 * *$ & $-.105(31 \%)$ & $-.35 * *$ & $.23^{*}$ & $-.081(17 \%)$ \\
\hline M.Ed. & $-.22+$ & .16 & $-.035(17 \%)$ & $-.22+$ & $.27^{*}$ & $-.059(18 \%)$ & $-.22+$ & $.21^{*}$ & $-.046(10 \%)$ \\
\hline Total & & & -.211 & & & -.337 & & & -.466 \\
\hline
\end{tabular}

Note. Group, $\mathrm{n}=78$ (51 preterm, 27 full-term). Mediating effects of .04 or greater are bolded. M.Ed: maternal education

$\dagger \mathrm{p}<.10, * \mathrm{p}<.05, * \mathrm{p}<.01$ 
bioRxiv preprint doi: https://doi.org/10.1101/868547; this version posted April 18, 2020. The copyright holder for this preprint (which was not certified by peer review) is the author/funder, who has granted bioRxiv a license to display the preprint in perpetuity. It is made available under aCC-BY-NC-ND 4.0 International license.

MATHEMATICS SKILLS IN PRETERM CHILDREN
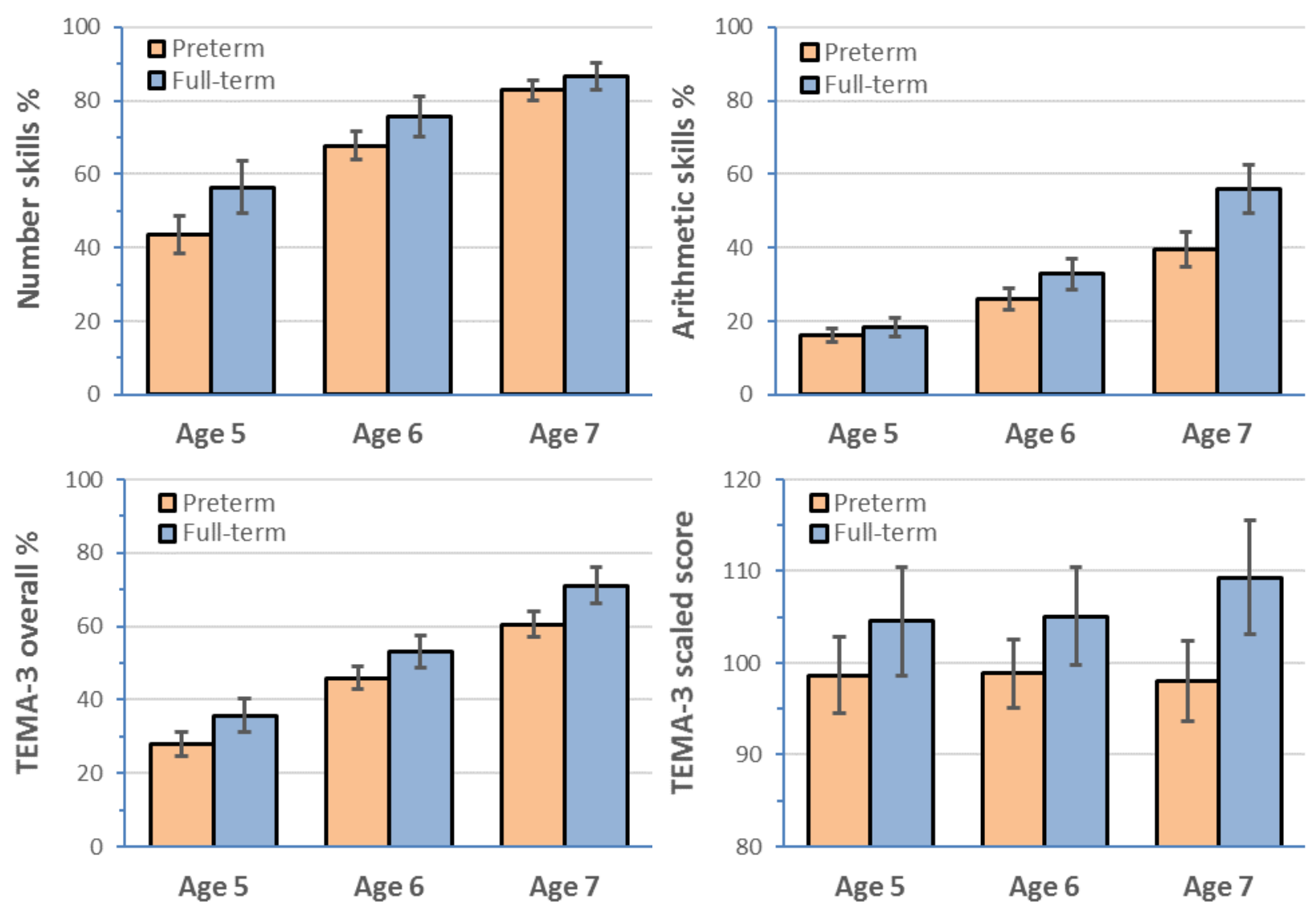

Figure 1. Development of mathematics skills from age 5 to 7 for preterm and full-term groups. TEMA-3: Test for Early Mathematics Ability, 3rd edition. Error bars are 95\% confidence intervals. 
bioRxiv preprint doi: https://doi.org/10.1101/868547; this version posted April 18,2020 . The copyright holder for this preprint (which was not certified by peer review) is the author/funder, who has granted bioRxiv a license to display the preprint in perpetuity. It is made available under aCC-BY-NC-ND 4.0 International license.

MATHEMATICS SKILLS IN PRETERM CHILDREN
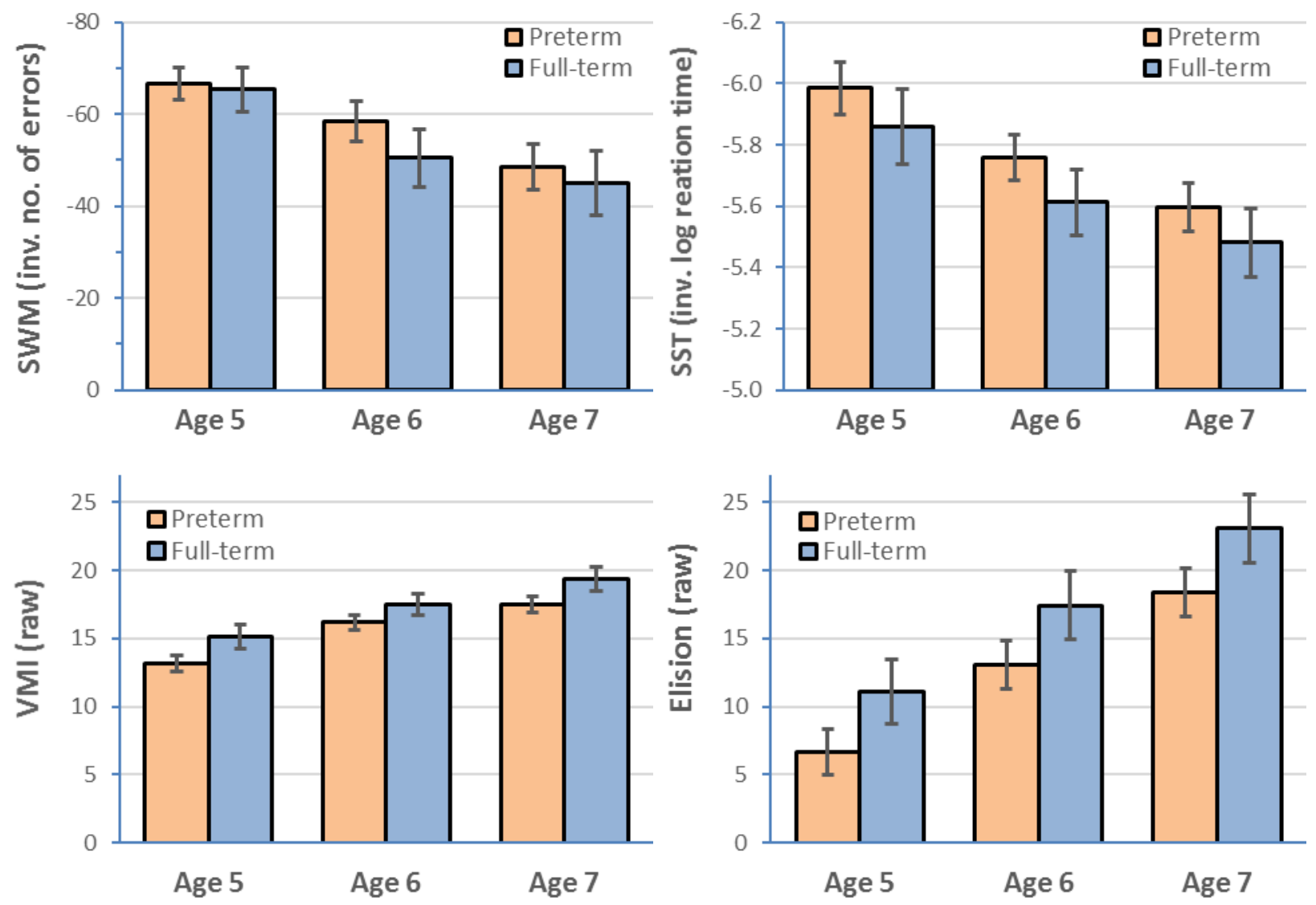

Figure 2. Development of cognitive functions from age 5 to 7 for preterm and full-term groups. SWM: spatial working memory, SST: stop signal task/test of inhibitory control, VMI: visualmotor integration, Elision: test of phonological processing. Error bars are $95 \%$ confidence intervals. 

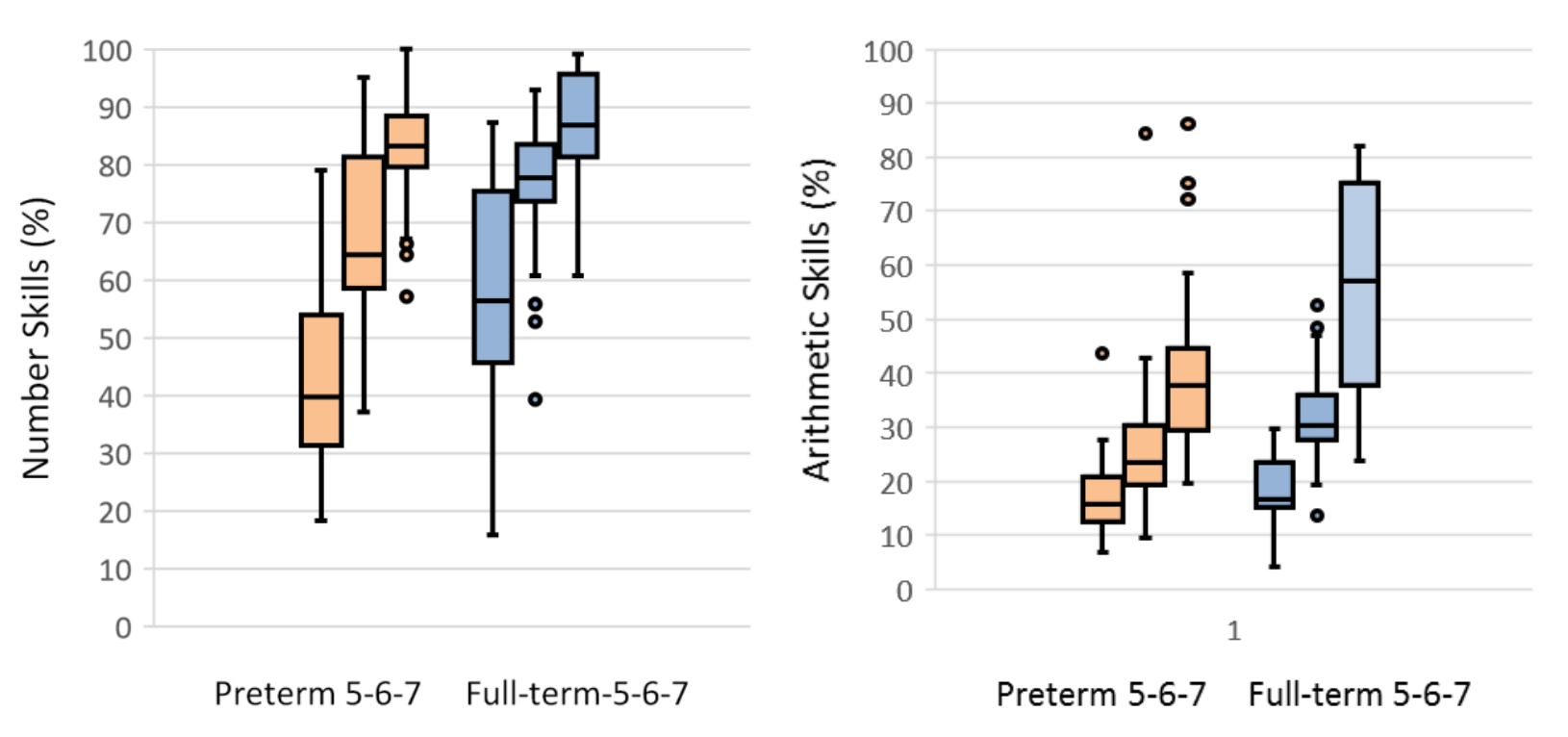

Figure 3. Box-and-whisker plots for preterm and full-term groups from age 5 to 7 . The box includes scores from the 25 th to the 75 th percentile. The whiskers indicate the lowest and highest scores that are not extreme. Extreme scores, defined as any 1.5 times the interquartile range below the 25 th or above the 75 th percentile, are indicated with circles. 


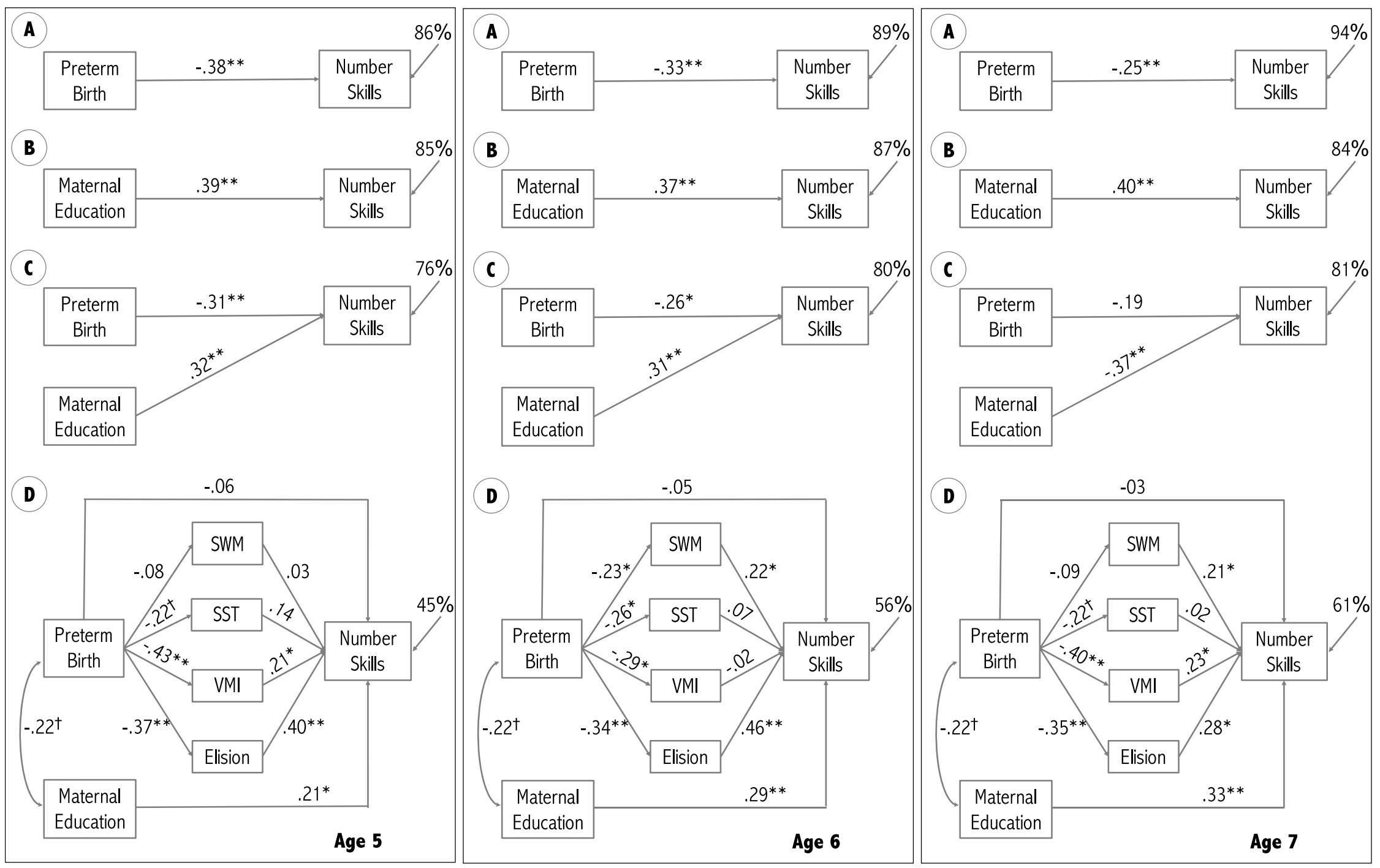

Figure 4. Path diagrams showing the link between group and maternal education, and their effect on number skills over time. A: Effect of preterm birth, B: Effect of maternal education, C: Joint effect of preterm birth and maternal education,

D: Mediation models showing the mediating effect of SWM (spatial working memory), SST (stop signal task/inhibitory control), and VMI (visual-motor integration), and Elision (phonological processing) between group and mathematics skills. Coefficients on lines with a one directional arrow represent standardized betas, coefficients on lines with bi-directional arrows are the simple correlation coefficients $(r) . \dagger p<.10, * p<.05, * * p<.01$ 


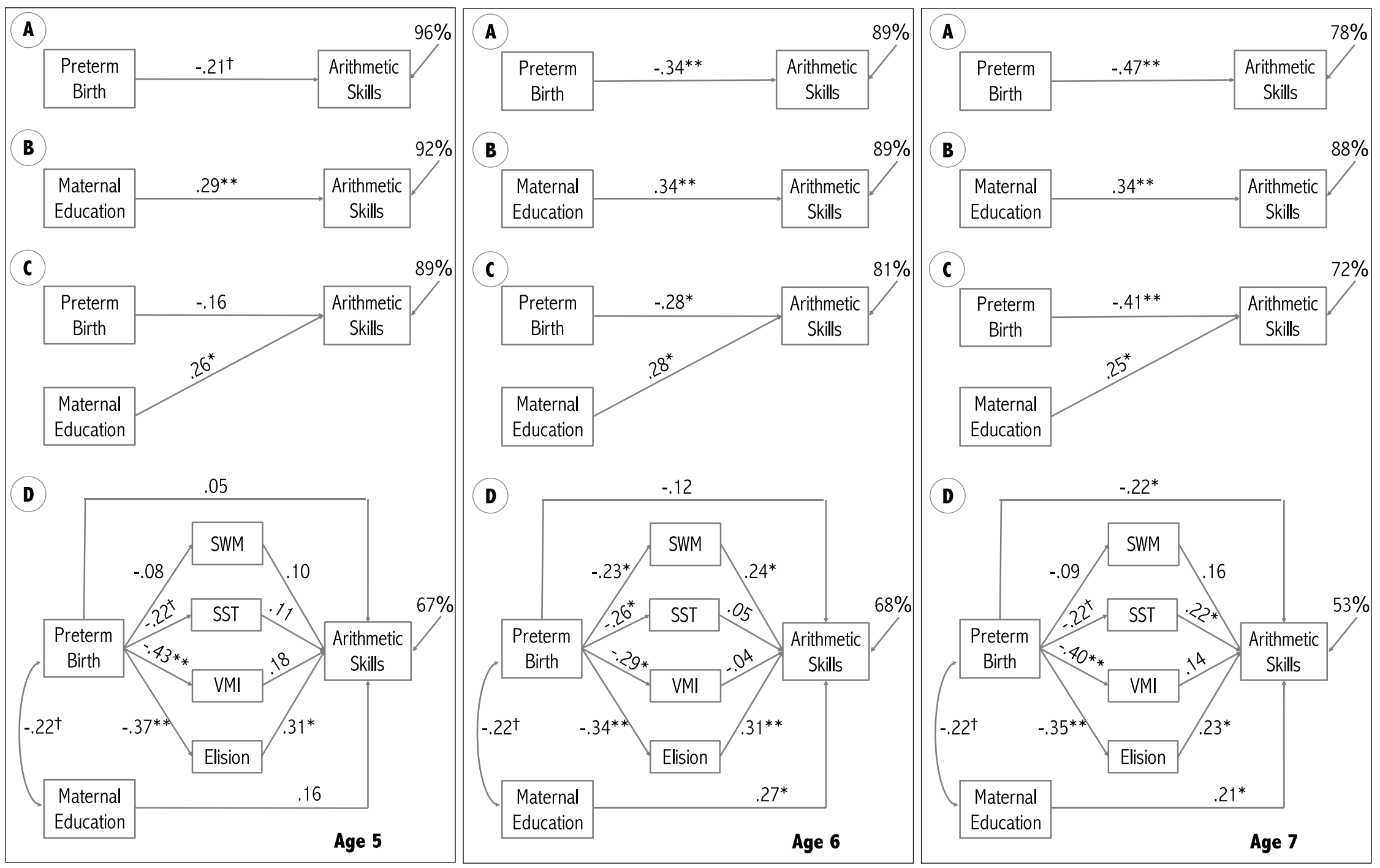

Figure 5. Path diagrams showing the link between group and maternal education, and their effect on arithmetic skills over time. A: Effect of preterm birth, B: Effect of maternal education, C: Joint effect of preterm birth and maternal education, D: Mediation models showing the mediating effect of SWM (spatial working memory), SST (stop signal task/inhibitory control), and VMI (visual-motor integration), and Elision (phonological processing) between group and mathematics skills. Coefficients on lines with a one directional arrow represent standardized betas, coefficients on lines with bi-directional arrows are the simple correlation coefficients $(r) . \dagger p<.10, * p<.05, * * p<.01$ 